\title{
RECENT NITROGEN DEPOSITION IN POLAND MONITORED WITH THE MOSS PLEUROZIUM SCHREBERI
}

\author{
Pawe Kapusta ${ }^{1}$, Grażyna SZareK-ŁuKaszewsKa, Barbara GodZIK \\ \& BARBARA ŁOPATA
}

\begin{abstract}
In this study, atmospheric deposition of nitrogen was determined for Poland by moss biomonitoring. Nitrogen content was measured in the moss Pleurozium schreberi (Willd. ex Brid.) Mitt. sampled in 2010 from 320 sites evenly distributed throughout the country. Mosses (green parts) contained an average 1.56\% nitrogen. The result places Poland among the European countries most polluted by airborne nitrogen. The highest nitrogen concentrations were found in mosses from the central and southern parts of the country, and the lowest in samples from some eastern and northern regions. Multiple regression showed that this variability was due mostly to nitrogen emissions from agricultural and industrial areas (moss nitrogen was positively associated with the consumption of mineral nitrogen fertilizers and the magnitude of particulate pollution). Some details of the spatial variability of the nitrogen data indicate that local and regional point sources of pollution (e.g., chemical plants) played an important role in shaping the nitrogen deposition pattern.
\end{abstract}

Key words: nitrogen deposition, biomonitoring, moss survey, Pleurozium schreberi, spatial pattern

Pawet Kapusta, Grażyna Szarek-Lukaszewska, Barbara Godzik \& Barbara Łopata, W. Szafer Institute of Botany, Polish Academy of Sciences, Lubicz 46, 31-512 Kraków, Poland; e-mail: p.kapusta@botany.pl

\section{INTRODUCTION}

Nitrogen is an essential nutrient. A deficiency of it greatly limits the growth and reproduction of organisms but an excess can be deleterious, as it causes eutrophication and acidification of habitats (Vitousek et al. 1997). Such consequences are increasingly observed in the natural environment, resulting from the rapid increase in anthropogenic emissions of nitrogen in recent decades. Some estimates show that on a global scale, human activity, particularly fossil fuel burning, crop fertilization and anthropogenic $\mathrm{N}_{2}$ fixation (legume and rice cropping), produces almost as much reactive nitrogen as natural sources (Vitousek et al. 1997; Peńuelas et al. 2012). In Europe, atmospheric deposition of nitrogen may be affecting most of the natural and seminatural ecosystems (Posch et al. 2012). Its adverse effects include loss of biodiversity, changes in species composition, changes in biomass and increased susceptibility to parasites (Bobbink et al. 2010).

\footnotetext{
1 Corresponding author
}

The first step toward coping with the problem of elevated environmental levels of nitrogen is to understand its spatial and temporal variation. Direct measurements of airborne nitrogen (and many other pollutants) are generally expensive and difficult. They require sampling stations, sometimes equipped with measurement instruments that need a power supply, and also maintenance (including servicing and protection against vandalism). For this reason, alternative methods of assessing atmospheric deposition of nitrogen are sought. One of the most promising ones is passive moss biomonitoring, by which native species of mosses are collected from the study area and analyzed for the content of a target element (Rühling \& Tyler 1968; Tyler 1971). Since the 1970s this method has been widely used to estimate the spatial and temporal patterns of heavy metal contamination (Onianwa 2001; Zechmeister et al. 2003). Recently it was successfully used to assess nitrogen pollution of the air (Poikolainen et al. 2009; Harmens et al. 
2011, 2013). Poland monitored nitrogen atmospheric deposition with the use of mosses for the first time in 2010. This paper presents the results of that survey.

\section{Material AND METHODS}

Mosses Pleurozium schreberi (Willd. ex Brid.) Mitt. were collected in summer 2010 from 320 sites evenly distributed throughout the country (Fig. 1a). The sites were positioned with a GPS receiver, identified by province (each of 16; provinces are Poland's largest administrative divisions) and described in terms of habitat type; most of them (over $80 \%$ ) were situated in pine forests and the rest were in other types of forest habitat. The sites were at least $300 \mathrm{~m}$ distant from main roads and residential areas, and at least $100 \mathrm{~m}$ distant from other roads and single buildings. At each site, moss samples were taken from several moss carpets growing under tree canopy gaps (to reduce the effect of throughfall chemistry) and bulked into one composite sample.

Green parts of mosses, representing approximately the last three years of growth, were subjected to chemical analysis. Plant material was ground and dried at
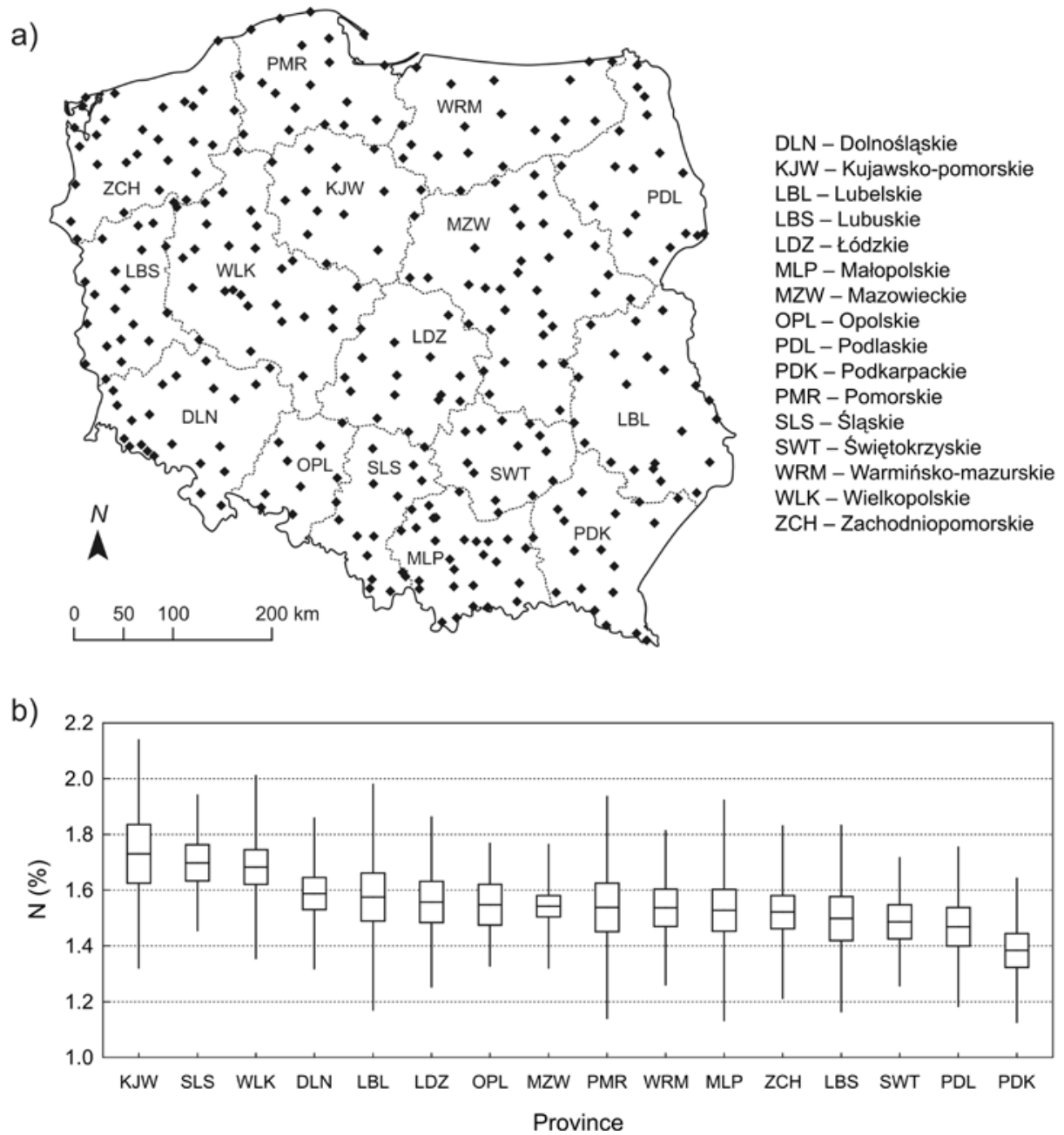

Fig. 1. The 2010 moss monitoring survey in Poland: (a) location of 320 sampling sites across the country, divided into provinces (three-letter codes for provinces explained at right); (b) mean, standard error (boxes) and standard deviation (whiskers) of nitrogen concentration in mosses calculated for provinces (provinces given in decreasing order of mean values). 
$70-80^{\circ} \mathrm{C}$. Total nitrogen content was determined from homogenized samples by the Kjeldahl method using a Kjeltec 2300 (Foss Tecator). Moss standards M2 and M3 were used to check the quality of chemical analyses (Harmens et al. 2013).

The 16 provinces were described in terms of consumption of mineral nitrogen fertilizers applied in agricultural areas and air pollution indices (number of industrial plants most harmful to air purity, total emissions of particulate pollutants and nitrogen oxides from these plants). These data, taken from the 2011 Annual Report by the Central Statistical Office (Anonymous 2011), were used, after testing for multicolinearity, in a multiple regression to explain the variability in the nitrogen content of mosses (averaged for each province; $\mathrm{N}=16$ ). One-way ANOVA of all the nitrogen data $(\mathrm{N}=320)$ was performed to test the statistical significance of differences between provinces. The nitrogen data were interpolated over the study area (Poland) using ordinary kriging to illustrate the spatial pattern of nitrogen deposition indicated by mosses. Prior to statistical analysis, the variables (dependent and independent) were transformed with a logarithmic or exponential function to obtain normal distributions. The statistical analysis employed STATISTICA 9 (StatSoft Inc. Tulsa, Ok., USA), and the geostatistical analysis used Surfer 8 (Golden Software Inc., Golden, Col., USA).

\section{RESULTS AND DISCUSSION}

In the 2010 Polish moss survey the total nitrogen content of mosses averaged $1.56 \%$ (range $0.78-$ $2.86 \%$ ), twice the value obtained for the reference country, Finland, and comparable to the values recorded for some European countries most affected by airborne nitrogen deposition (Harmens et al. 2013). The result is in agreement with the data on emissions of nitrogen compounds from Europe (Anonymous 2012), which showed that Poland released one of the region's largest amounts of nitrogen into the atmosphere.

One-way ANOVA showed no significant differences in total nitrogen content between the 16 provinces. This is likely a consequence of the high variability of the data on a small spatial scale, reflected in the standard deviations shown in Fig. 1b. Such variability suggests the effects of multiple local sources of nitrogen pollution, such as areas of intensive livestock farming (Pitcairn et al. 2006).
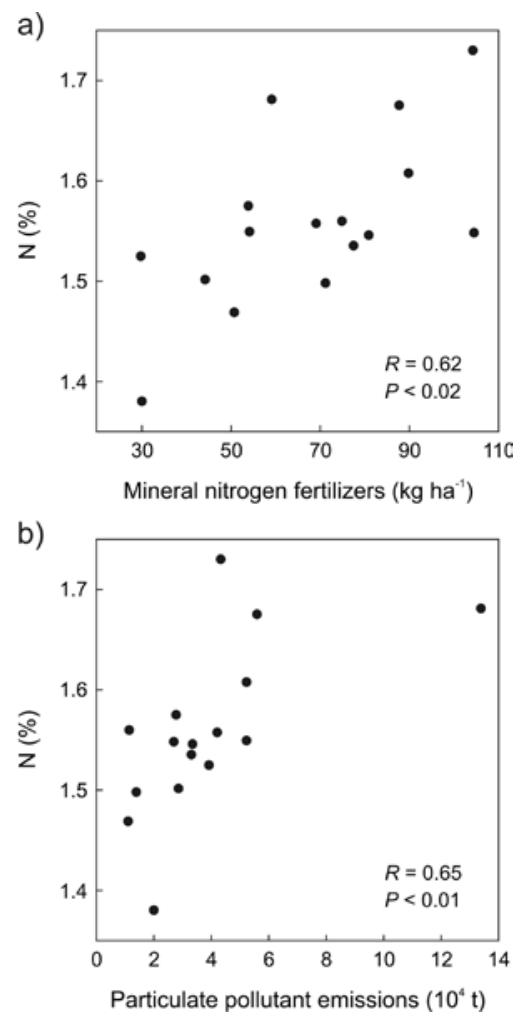

Fig. 2. Simple correlations between nitrogen concentration in mosses averaged for provinces $(\mathrm{N}=16)$ and (a) consumption of mineral nitrogen fertilizers ( $\mathrm{kg}$ per 1 ha agricultural land per province) and (b) particulate emissions from industrial plants most harmful to air purity (thousand tons per province).

The between-province variation, though not statistically significant, was not random. It nicely corresponded with two variables selected to characterize the environmental quality of the provinces: the intensity of mineral nitrogen fertilization of agricultural land (Fig. 2a) and the magnitude of particulate emissions (Fig. 2b). In multiple regression these independent variables explained nearly $66 \%$ of the variation in the total nitrogen content of mosses (adjusted $R^{2}=0.657, F_{2,13}=15.39$, $P<0.001)$ and had fairly equal effects on the dependent variable as indicated by standardized (beta) coefficients ( 0.540 for mineral nitrogen fertilization and 0.568 for particulate emissions).

The spatial pattern of nitrogen deposition presented by the moss data is shown in Fig. 3. The highest values were recorded in the center of the 


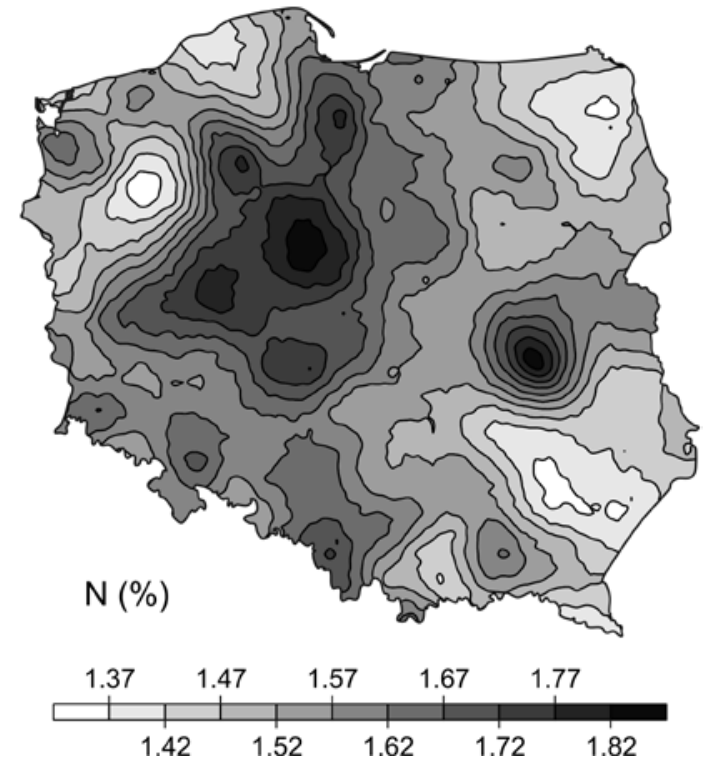

Fig. 3. Spatial pattern of atmospheric nitrogen deposition in Poland as indicated by biomonitoring with mosses.

country and the lowest values in the northwestern, northeastern and southeastern parts. This variability probably reflects differences in the intensity of agricultural production. Agriculture, both crop cultivation (associated with fertilizer use) and livestock farming, is mainly a source of reduced nitrogen such as ammonia, ammonium and amines (Behera et al. 2013). Its deposition, predicted for Poland on the basis of the FRAME model (Kryza et al. 2014), approximately agrees with the results we obtained from biomonitoring.

Multiple regression revealed another important component of the described spatial pattern (Fig. 3): particulate emissions. Such pollutants arise largely from combustion processes (energy industry, household heating, road transportation) and are accompanied by the release of significant amounts of nitrogen (in oxidized form) into the atmosphere (Anonymous 2012). We believe that the elevated nitrogen concentrations in the mosses in the southern, most populated and industrialized parts of the country are an effect of this type of emission, especially since they correspond with the FRAME model estimates of $\mathrm{NO}_{\mathrm{x}}$ deposition (Kryza et al. 2014).
The spatial pattern of nitrogen deposition also seems to be shaped by the presence of strong point sources of nitrogen emissions. These sources certainly include the large chemical plants, in particular those that manufacture artificial fertilizers. The largest are situated in Puławy (responsible for the hotspot of high values in the middle of eastern Poland), and the towns of Police, KędzierzynKoźle and Tarnów-Mościce.

This study showed that Poland is one of the countries most exposed to the adverse impacts of nitrogen in Europe. According to the moss data, excessive nitrogen deposition covers more than half of Poland's territory. This means that many ecosystems, among them perhaps the most valuable ones, may be damaged by eutrophication or other effects of nitrogen pollution. This has been observed in other countries at sites including oligotrophic forest (Dirnböck et al. 2014) and seminatural grassland (Helsen et al. 2014). In view of temporal trends and long-term simulations of nitrogen emissions/deposition for Europe (Posch et al. 2012), the situation should improve gradually in the coming decades. There is a need to continue monitoring airborne nitrogen and to study changes in the diversity, structure and condition of plant/ animal communities in habitats potentially most vulnerable to the effects of excess nitrogen.

ACKNOWLEDGEMENTS. We are grateful to the anonymous reviewers for helpful suggestions on the manuscript. This study was financially supported by the Polish Ministry of Science and Higher Education (grant no. N 304 356138) and by the W. Szafer Institute of Botany (Polish Academy of Sciences) through its statutory funds.

\section{REFERENCES}

AnONYmous 2011. Environment 2011. Główny Urząd Statystyczny, Warsaw.

ANONYMOUS 2012. European Union emission inventory report 1990-2010 under the UNECE Convention on Long-range Transboundary Air Pollution (LRTAP). EEA, Copenhagen.

Behera S. N., Sharma M., Aneja V. P. \& BalasubramaNIAN R. 2013. Ammonia in the atmosphere: a review on emission sources, atmospheric chemistry and deposition on terrestrial bodies. Environmental Science and Pollution Research 20(11): 8092-8131. 
Bobbink R., Hicks K., Galloway J., Spranger T., Alkemade R., Ashmore M., Bustamante M., Cinderby S., Davidson E., Dentener F., Emmett B., Erisman J.-W., Fenn M., Gilliam F., Nordin A., Pardo L. \& De Vries W. 2010. Global assessment of nitrogen deposition effects on terrestrial plant diversity: a synthesis. Ecological Applications 20(1): 30-59.

Dirnböck T., Grandin U., Bernhardt-Römermann M., Beudert B., Canullo R., Forsius M., Grabner M.-T., Holmberg M., Kleemola S., Lundin L., Mirtl M., Neumann M., Pompei E., Salemaa M., Starlinger F., StaszewsKi T. \& UzięBŁo A. K. 2014. Forest floor vegetation response to nitrogen deposition in Europe. Global Change Biology 20: 429-440.

Harmens H., Norris D. A., Cooper D. M., Mills G., Steinnes E., Kubin E., Thöni L., Aboal J. R., Alber R., Carballeira A., Coşkun M., De Temmerman L., Frolova M., González-Miqueo L., Jeran Z., Leblond S., Litv S., Maňkovská B., Pesch R., Poikolainen J., RüHling Å., Santamaria J. M., Simončič P., Schröder W., Suchara I., Yurukova L. \& Zechmeister H. G. 2011. Nitrogen concentrations in mosses indicate the spatial distribution of atmospheric nitrogen deposition in Europe. Environmental Pollution 159: 2852-2860.

Harmens H., Norris D., Mills G. \& THE Participants of moss SURVEY 2013. Heavy metals and nitrogen in mosses: spatial patterns in 2010/2011 and long-term temporal trends in Europe. ICP Vegetation Programme Coordination Centre, Centre for Ecology and Hydrology, Bangor.

Helsen K., Ceulemans T., Stevens C. J. \& Honnay O. 2014. Increasing soil nutrient loads of European semi-natural grasslands strongly alter plant functional diversity independently of species loss. Ecosystems 17: 169-181.

Kryza M., Mill W., Dore A. J., Werner M. \& Blaś M. 2014. Calculation of sulphur and nitrogen deposition with the FRAME model and assessment of the exceedance of critical loads in Poland. Ecological Chemistry and Engineering S 20(2): 279-290.
ONIANWA P. C. 2001. Monitoring atmospheric metal pollution: a review of the use of mosses as indicators. Environmental Monitoring and Assessment 71: 13-50.

Peńuelas J., Sardans J., Rivas-Ubach A. \& Janssens I. A. 2012. The human-induced imbalance between $\mathrm{C}, \mathrm{N}$ and $\mathrm{P}$ in Earth's life system. Global Change Biology 18(1): 3-6.

Pitcairn C., Fowler D., Leith I., Sheppard L., Tang S., SutTon M. \& Famulari D. 2006. Diagnostic indicators of elevated nitrogen deposition. Environmental Pollution 144: 941-950.

Poikolainen J., Piispanen J., Karhu J. \& Kubin E. 2009. Long-term changes in nitrogen deposition in Finland (1990-2006) monitored using the moss Hylocomium splendens. Environmental Pollution 157: 3091-3097.

Posch M., Slootweg J. \& Hettelingh J.-P. (eds) 2012. Modelling and mapping of atmospherically-induced ecosystem impacts in Europe. CCE Status Report 2012. Coordination Centre for Effects, RIVM, Bilthoven.

RüHLING Å. \& TYler G. 1968. An ecological approach to the lead problem. Bot. Not. 121: 321-342.

TYLER G. 1971. Moss analysis - a method for surveying heavy metal deposition. In: H. M. ENGLUnd \& W. T. BerRY (eds), Proceedings of the Second International Clean Air Congress, pp. 129-132. Academic Press, New York.

Vitousek P. M., Aber J. D., Howarth R. W., Likens G. E., Matson P. A., Schindler D. W., Schlesinger W. H. \& Tilman D. G. 1997. Human alteration of the global nitrogen cycle: sources and consequences. Ecological Applications 7: 737-750.

Zechmeister H. G., Grodzińska K. \& Szarek-ŁukaszewSKA G. 2003. Bryophytes. In: B. A. Markert, A. M. Breure \& H. G. Zechmeister (eds), Bioindicators and biomonitors principles, concepts and applications. Trace metals and other contaminants in the environment, pp. 329-375. Elsevier, Amsterdam. 